\title{
Research on the People's Survival in Traditional Chinese Opera
}

\author{
Tang Haiyan \\ Department of Music and Dance, Changsha Normal University, Changsha, Hunan 410100
}

Keywords: Drama Performance, People Skills, Research

\begin{abstract}
The characters in opera performances are one of the most outstanding features that draw attention of the audience. In general, the characters in opera repertoire are mainly divided into traditional acrobatics classes, artists' self-creation and magic. These characters are absolutely essential to the stage performances which play roles in shaping characters, enriching performance means and creating real situations. The sources of these skills are usually acrobatics and martial arts. Some of them are taught by artistes, while others are created according to the stage. For long-term development of theatrical performances, it is necessary to give full play to the effects and functions brought by the characters.
\end{abstract}

\section{Introduction}

As with other performances, the performance of the traditional opera requires the efforts of "one minute on stage and 10 years on the stage." However, the performance of opera performances in the audience is mainly reflected in the aspects of action. To sum up, there are mainly tactics, handkerchief, fan work, each method and effort include complex content and form, such as the simplest way and includes a wide range of orchids, praise means, derogatory meaning, character means, etc., usually measure the size of the play, the professional level of the troupe, whether or not the performer has been trained in the band, etc., are usually based on the performance of basic skills as a measure of the basic indicators [1]. However, if an artist wants to become a red person in the view of the audience, becoming the nostalgia of the box office is not enough simply by virtue of basic skills. It must have the so-called unique skills in opera. What we usually call the drama unique skills including two meanings: first, by a few artists to master some of the special acting skills, such as changing face, blowing fire, the other is the artist through their own art of mining excavation and comprehension of their own created an acting, this acting is arbitrary, only the creator will use [2]. Judging from the performance of the current drama, the characters are well received by audiences. However, judging from the study of the academic period, it is seldom found that there are scholars who have devoted themselves to the study of the theory of opera dances, from the importance of the character's perfection in performance of the opera from the point of view, it is imminent to study the character's uniqueness. This article will therefore start the relevant discussion.

\section{The characters in the opera produced unique skills}

\subsection{Heritage of traditional acrobatics, martial arts and other skills}

Different opera artists have different origins. For example, some artists come from the Liyuan family, others from the Kobar, and others from migrant workers and merchants. Some of the opera actors themselves are acrobats and martial artists. Some of the opera actors who come from acrobatics and martial arts will naturally use their unique skills during the performance of the opera. In order to win the audience's attention, he will also talk about dramas and operas and other entertainers in the process of artistic training so that he can master some unique skills during the performance of the opera and present it in appropriate performance occasions[1]. For example, the hanging braids mentioned in many operas are an acrobatics program flourished in the Qing Dynasty. Because people were advocated during the Qing dynasty, related artists performed their work on braids, such as turning long, soft mats into god whips Feng Jicai wrote such related stories in the novel Whiplash. Many artists began to frequently use their own hanging braids on the stage 
performances. For example, the performers often whipped at Beam, performers swing back and forth from the body. In addition, there was a strong pressure to show the liar in the performance, fixing the performers' limbs, and lifting 10 barrels of water with braids.

\subsection{Originated in the creation of witch artist}

One of the repertoires that exist in the rich drama of our country is the Nuo opera. Usually, we call it Western opera, opera, Jianghuai incense and so on are familiar with Nuo opera. There are still some drama tracks evolved from the Nuo opera, such as the so-called Jiangsu's Yangju, Nantong's dramas and so on are evolved from the Nuo opera, or Nuo opera or direct blood relationship, Nuo opera artists usually come from wizards. In order to show their rich deities, they are going to add some special acting skills to the stage performances, such as the mountaineer, the sea of fire, the cut belly, etc[2]. In general, the evolution from sacrificial activities of the opera is more mixed with unique skills, such as Yang Hongtao artist, were born in a family of incense, since childhood with his father Chen Zhicai learn incense, and practice turning the table, string knife circle, and turn ring hard work, so its performance Yang plays often include some martial arts skills in appropriate scenes.

\subsection{Created by opera artists themselves}

Many artists, in order to make their performances different from others, will create some special skills that are different from those of the average person in order to gain the audience's favor and love, and at the same time it will be of great help to the promotion of personal reputation and honor. This unique innovation not only makes the performance of the show more intense, but also conducive to enrich the means and means of drama, therefore, the artist is willing and long-term research in the real sense of innovation and innovation. These unique skills will only be used by creators themselves, and thus have the characteristics of being dead[2]. For example, the entertainer Zheng Kun-hsing in the performance of "Guan Gongxian St." and clever use of the Qigong face. Before taking office, he inhaled two dry cigarettes without venting. After taking office, all the yellow cigarettes were sucked out. For the moment, his face turned jujube red and the show ended. Another example is the Sichuan artist swallow in the "Double Flag" performance encounter Dragonji chase, they borrowed silver Yan curtain action, flew Taiwan's estranged distance, and at the time of landing, in the audience's head slightly, then fly back to the stage.

\section{The types of characters in the opera}

According to incomplete statistics, there are more than 300 unique types of present performance of theatrical performances. The types of unique activities presented in different repertoires are also different. However, in general, there are more operas with more than 200 years of history, the degree is in direct proportion to the amount of uniqueness it presents. In addition, the operas with higher status in the performance drama also contain relatively greater quantities of unique skills, and vice versa. Such as Shaoxing Opera, Shanghai Opera, Huangmei opera contains almost no unique skills, because these plays have a short history of development, the performance of the ugly performance is also low. Simple and vivid manifestation, mainly includes the following three types[3].

\subsection{Traditional acrobatics type}

The traditional acrobatics class unique skills include climbing pole, hit the fork, channeling circle, rolling cylinder, climbing pole is a unique play in the Qin and Han dynasties, also known as the edge of the pole, because this must live all over the country, so in many theatrical performances will appear. For example, in the opera "Kowloon Cup", "savage ship" are widely covered in this unique skill, usually includes the action of upside down, the devil on a large iron bridge, pouring a flag and so on, Wannan repertoire show . The included climbing pole movements are usually independent of the Rooster, gold hook upside down, boy meditation, turtle paddling and so on. Channeling circle is also a traditional skill, mainly divided into string ring and string knife ring two. 
Fire ring is a cross across the edge of the fire, knife ring is inserted in the edge of the edge of the blade, the tip up, the artist needs to channel a few laps or laps on the tip, and can not touch to the tool holder. In the performance of the show to express the difficult road or difficulties, will be demonstrated in this technique to show the sinister environment and the character itself complex.

\subsection{The needs of the plot and creation of their own stunts}

We usually talk about the 18 Arhats, hanging braids, male and female eyes, face, flying beads are all artists in the performance process, according to the plot of their own stunts. The male and female eyes are used to show the creation of character images. For example, we often see Lu Zhishen in Drunken Mountain Gate and Zheng Ziming in "Dragonshed". The main manifestation is the artist's eyes closed one eye, with the rhythm of constantly rotating the eye, and to combine facial expressions and movements. Eighteen arhats originated from Kunqu Opera entertainers. In different series of performances, the Eighteen arhats are different, so eighteen Arhats have a great disparity in the form of performances[3]. However, most of the actors in the show perform 18 legs, there will be one leg and not leg movements, if there is no real effort, is not able to be stable and vivid eighteen arhats. However, at the same time, local operas are also presented in different places. The changing face of Sichuan Opera usually has the characteristics of sobering, changing colors, changing faces, and changing faces. The first two face-changing forms and other repertoire Almost, the difference is the back of the two face forms[4].

\subsection{Magic type of stunt}

Many of the artists in the arena showcase the unique skills that are acquired through hard work under the stage. However, at the same time, there are many stage art and unique skills that are not real kung fu. The seven holes in the magic bleed, catch the fire, covet three feet, such as in the "Anan send ${ }^{\mathrm{r}}$ ice" repertoire, ginger in order to regain the steamed white rice, will be superimposed on the seven tiles pounding day and night, but the endless head has not been any harm, these tiles are touched and chemically treated, so they do not hurt anyone. Another example is "Ding Huang's" in order to clear their own bribery is too suspicious, they asked the money to touch the money in the form of Ding Huang proved innocent, Ding Huang will be directly from the boiling pan out of five .In fact, $95 \%$ of the boiling liquid in the pan is vinegar, and $5 \%$ of the oil is oil. Because the density of the oil is smaller than the density at the place, it floats on the vinegar. The boiling point of the vinegar is $40{ }^{\circ} \mathrm{C}[3]$. Under, no one's hand will be scalded.

\section{The role of the characters in the opera and function}

\subsection{Create a real situation in line with the performance requirements}

Survival has the authenticity of the audience from the real world into a dramatic situation, so that the audience believe that what is happening is true, such as in the "Survival Saburo" repertoire performance, dead Yan Xijiao order Lover Zhang Wenyuan accompanied to the hell to play, playing Yan Xijiao entertainer with a towel hooked Zhang Wenyuan artists neck, and gently lift it up, showing the state is the hands out of the sleeve, and the whole person with Yan Xijiao action[4]. The change swings and shakes from side to side. This shows the situation, let the audience believe that the eyes of Zhang Wenyuan is already a ghost. In addition, the performance of this technique is often played in Sichuan, Hunan, Anhui and other repertoire performances, the fork method has many forms of expression, the most thrilling are the main three incense, playing the mountain, buried in the form of fork. The form of performance has a certain risk, so generally in the show before the performance, the troupe will be the performer and the performer signed the contract, the main content is played as a fork artist in the event of danger, by the relevant theater to be responsible for the audience[2]. When watching the related cross-tabulation program, sometimes horrified and sometimes scared, completely forgetting that he is just a sunstroke identity in the theater, so this form of stunt shows can make the audience feel the authenticity of the show in a particular situation. 


\subsection{Help people create a flexible and vivid image}

The forms of singing, acting and speaking, as we usually say, all convey to some extent the emotions, qualities and personalities of the characters. However, it is very difficult to impress the audience. However, to a different effect, showing a vivid and vivid character, to the audience left a deep impression. Therefore, the unique skills and performance should be effectively integrated in the drama, such as Wang Chuan Song in the "down hill" play a monk because of a pair of shoes nipped dangling water, nun "someone came" to scare him, monk anxious, two pairs Shoe flew instantaneously and fell on both banks of the river, from which you can see the inner truthful, but timid character of the little monk. There are many performances in the show, in a unique form to show the character of the character, so as to impress the audience[4].

\subsection{Enrich the repertoire performance form}

Survival is another effort beyond the basic skills an artist must master. Adding extravagant forms to the performance of the show can bring more glamor and charm to the performance. For example, in "Downward Mountain", in order to express the joy of the liberation of Monk from the bondage of Buddhism, the young monk through the strong and shoulder of the beads so beads slowly slow rotation on the neck, slipped on the neck to shoulder, thrown on the air, spin a few times before falling back to shoulder. This performance is absolutely delightless performances and singing methods, and can feel the happiness of the little monk, but also to feel the unique performance of the show. Although the form of unique skills is more cumbersome, the audience did not take the trouble to continue to applause. This was mainly because of the different forms of performance that allowed the audience to simultaneously understand the beauty and pleasure of the performance from multiple perspectives.

\section{Conclusions}

Unique skill is a comprehensive performance of traditional Chinese opera performance and is the key performance of the show, but in recent years, unique performance in the show the number and form of play less and less, mainly because Survival in some scenes too bloody terror, for the life of the artist's life-threatening, but also has little to do with the characters, it was banned. But what I have to say is that the traditional drama track needs to be inherited and developed. Apart from making innovations and efforts in transmitting script, performance and music, it is also necessary to attach sufficient importance to the unique skills in opera performances. Only on the basis of inheritance, make constant innovations and changes in the form of unique skills and ensure that they meet the needs of contemporary drama performances and contribute to the rich development of Chinese drama.

\section{References}

[1] Zhu Hengfu. "Survival" in Traditional Chinese Opera Performances [J]. Theater Arts, 2015 (01): 108-115.

[2] Wang Jiucheng. Chinese opera unique performance of the first show held in Beijing [J]. Opera Arts, 2000 (04): 37-39.

[3] Lv Tianlu. Chinese opera stunts once again conquered the Hong Kong opera fan [N]. China Culture Daily, 2004/11/01(3), 22-28.

[4] Sheng Kai. Fantastic adventure thrilling - Chinese opera "unique" in Hong Kong [J]. Contemporary drama, 2002 (01): 61-64. 